\title{
Association between Serum Magnesium level and outcome in birth asphyxia
}

\author{
Gandhi K. ${ }^{1}$, Kumar Singh A. ${ }^{2 *}$, Mehta A. ${ }^{3}$, Sharma B. ${ }^{4}$, Chandra Tiwari H. ${ }^{5}$ \\ DOI: https://doi.org/10.17511/ijpr.2020.i07.08
}

\footnotetext{
${ }^{1}$ Karm chand Gandhi, Senior Resident, Department of Pediatrics, BRD Medical College, Gorakhpur, Uttar Pradesh, India.

2* Abhishek Kumar Singh, Assistant Professor, Department of Pediatrics, BRD Medical College, Gorakhpur, Uttar Pradesh, India.

3 Anita Mehta, Professor and Head, Department of Pediatrics, BRD Medical College, Gorakhpur, Uttar Pradesh, India.

4 Bhoopendra Sharma, Professor, Department of Pediatrics, BRD Medical College, Gorakhpur, Uttar Pradesh, India.

5 Harish Chandra Tiwari, Assistant Professor, Department of Community Medicine, BRD Medical College, Gorakhpur, Uttar Pradesh, India.
}

Introduction: Magnesium ( $\mathrm{Mg}$ ) has been found to block the NMDA ion channel under resting conditions, occupying a binding site within the ion channel. The block is voltage-dependent and is overcome during axonal depolarization that occurs with hypoxia-ischemia. The systemic administration of magnesium after a stimulated hypoxic ischemia insult has been shown to limit neuronal injury in several animal models. Material and Methods: Cross-sectional study conducted at the Nehru Hospital, BRD Medical College, Gorakhpur (UP) in the Neonatal Intensive Care Unit of the pediatric department. Result: The prevalence of hypomagnesemia was $2.5 \%$. Hypomagnesemia was more on day 1 and day 3. Severe birth asphyxia had more prevalence of Hypomagnesaemia. On day one 4 out of 71 patients had hypomagnesemia. On day 2 no patient had hypomagnesemia, while on day three 4 patients had hypomagnesemia out of 75. A significant difference was found in hypomagnesemia on day 1 and day 2 as well as day 2 and day 3 . No patient had an antenatal highrisk factor in mother who had hypomagnesemia; there was no significant association between highrisk factors and hypomagnesemia. Conclusion: There should be more studies regarding hypomagnesemia in birth asphyxia and the association of hypomagnesemia with other parameters.

Keywords: Magnesium, Hypomagnesemia, Birth asphyxia, Outcome

Corresponding Author

Abhishek Kumar Singh, Assistant Professor, Department of Pediatrics, BRD Medical College, Gorakhpur, Uttar Pradesh, India.

Email: abhisheksingh.brd.gkp@gmail.com
How to Cite this Article

Gandhi KC, Singh AK, Mehta A, Sharma B, Tiwari HC. Association between Serum Magnesium level and outcome in birth asphyxia. Pediatric Rev Int J Pediatr Res. $2020 ; 7(7): 365-374$.

Available From

https://pediatrics.medresearch.in/index.php/ijpr/arti cle/view/625
To Browse

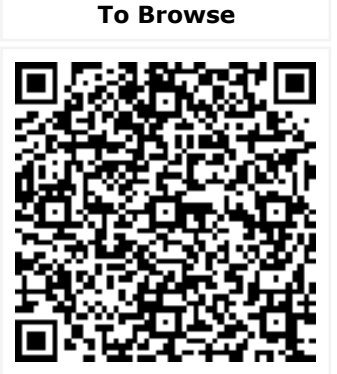

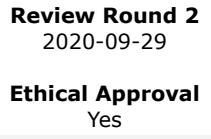

Review Round 3 


\section{Introduction}

The neonatal seizure is the commonest neurological dysfunction in the neonatal period; it is a paroxysmal alternation in neurological function like motor behavior and/or autonomic function and can occur at any gestational age.

The Neonatal central nervous system is particularly susceptible to seizures due to a combination of enhanced excitability, and low levels of the inhibitory neurotransmitter gamma-aminobutyric acid (GABA) [1].

Birth asphyxia is a serious clinical problem worldwide and contributes greatly to neonatal mortality and morbidity.

The combination of the decrease in oxygen supply (hypoxia) and blood supply (ischemia) results in a cascade of biochemical changes inside the body, whose events lead to neuronal cell death and brain damage. Continuous asphyxia also leads to multiple organ systems dysfunction [2].

World Health Organisation (WHO) defines Birth asphyxia as a failure to initiate and sustain breathing in a newborn at birth [3].

Definition of birth asphyxia is given by the ACOG, AAP includes the existence of 3 factors: Metabolic or mixed acidemia $(\mathrm{pH}<7)$ which is determined by umbilical cord arterial blood samples; APGAR score of $<3$ for longer than $5 \mathrm{~min}$; neurological manifestations; and multisystem organ dysfunction [4].

The incidence rate of clinical seizures varies from approximately 1.1 to 8.5 per 1000 live births [5].

The major causes of neonatal seizures are Hypoxicischemic encephalopathy (HIE), which represents about $50 \%$ of the causes of neonatal seizures.

Metabolic abnormalities, infection, intracranial hemorrhage, developmental anomalies, and other like inborn errors of metabolism are other causes of neonatal seizures [6].

The causes of seizures in preterm neonates are different from those seen in term neonates, where the HIE is the most frequent cause in term neonates, followed by cerebral malformations and metabolic disturbances.

In preterm neonates, intraventricular hemorrhage and infections are the most frequent causes [7].

\section{Magnesium}

Glutamate plays a critical role in the hypoxic ischaemic neuronal death, Magnesium (Mg) has been found to block the NMDA ion channel under resting conditions, occupying a binding site within the ion channel. The block is voltage-dependent and is overcome during axonal depolarization that occurs with hypoxia-ischemia. The systemic administration of magnesium after a stimulated hypoxic ischemia insult has been shown to limit neuronal injury in several animal models [8].

Magnesium plays important role in many physiologic functions including protein synthesis, bone development, and cell membrane function. There is some evidence to suggest a role for magnesium sulfate as a therapeutic neuroprotective agent along with therapeutic hypothermia in infants with hypoxic-ischemic encephalopathy, but studies are inconclusive ischemic insult and hypothermia may both play a role in altered magnesium levels in this population. Magnesium is an NMDA-receptor antagonist that may block the influx of calcium, therefore minimizing brain injury [9].

Increased magnesium consumption during the ischemic insult or ongoing losses caused by ischemic damage to renal glomeruli and tubules [10].

The release of excessive quantities of glutamate in HIE results in overstimulation of glutamate receptors, 2-aminomet hylphenylacetic acid (AMPA), kainite (KA), and N-Methyl-d-aspartate (NMDA), located on the postsynaptic membrane of nerve cells. This results in excitotoxicity [11].

Magnesium is the second most abundant intracellular cation and the fourth most abundant cation overall. Almost all enzymatic processes using phosphorus as an energy source require magnesium for activation [12].

Magnesium is involved in most biochemical reactions such as glycolysis and oxidative phosphorylation. Because magnesium is bound to adenosine triphosphate (ATP) inside the cell, shifts in intracellular magnesium concentration may help to regulate cellular, bioenergetics $[13,14,15]$.

Extracellularly magnesium ions block neurosynaptic transmission by interfering with the release of acetylcholine. Magnesium ions also may interfere with the release of catecholamines from the adrenal medulla. 
Magnesium has been proposed as being an endogenous endocrine modular of the catecholamine component of the physiologic stress response.

Approximately $60 \%$ of total body magnesium is located in the bone, and the remainder is in the soft tissues. In this soft tissue intracellular compartment, which comprises about $38 \%$ of total body magnesium, relatively higher concentrations are found in the skeletal muscle and the liver. Because less than $2 \%$ is present in the extracellular fluid (ECF) compartment, serum levels do not necessarily reflect the status of total body stores of magnesium.

- Magnesium: Approximately $30 \%$ of S. Mg (1 $\mathrm{mmol} / \mathrm{L}=2.4 \mathrm{mg} / \mathrm{dL}$ ) is in the protein-bound form, with the remainder in the ultrafiltrate portion. $7-8 \%$ of ultrafiltrate $\mathrm{Mg}$ is in ionic form, and the remainder is complexed to anions, particularly phosphate, citrate, and oxalate. Serum total $(\mathrm{tMg})$ of $0.92 \pm 0.13 \mathrm{mmol} / \mathrm{L}$ (mean $\pm 2 D$ ) in children is slightly higher than the adult values of $0.88 \pm 0.13 \mathrm{mmol} / \mathrm{L} .18$ Ionselective electrodes are used in the measurement of ionized $\mathrm{Mg}(\mathrm{iMg})$ in whole blood and seri. The clinical role of $\mathrm{iMg}$ (versus $\mathrm{tMg}$ ) in several disease states appears limited.

- Cellular Mg content of most tissues is 6-9 $\mathrm{mmol} / \mathrm{kg}$ net weight and most of this $\mathrm{Mg}$ is localized in membrane structures (e.g. microsome, mitochondria, plasma membrane). The much smaller pool of free $\mathrm{Mg}$ is localized in membrane structures. The intracellular content of $\mathrm{Mg}$ can be low despite normal serum concentrations. The measurement of the intracellular content of $\mathrm{Mg}$ can be low despite normal serum concentrations.

\section{Material and methods}

Study Design: An observational study - Crosssectional study

Study Centre: This is a hospital-based prospective study conducted at Nehru Hospital, BRD Medical College, Gorakhpur (UP) in the Neonatal Intensive Care Unit of the pediatric department.

Duration of Study: This study was conducted from July 2018 to July 2019.

Ethical Approval: The study is approved by the institutional ethical committee (IEC) BRD medical college Gorakhpur.
Consent: Written informed consent was taken from parents in the local language.

Case: All cases of birth asphyxia are admitted every day in the NICU which includes between the age group of birth to 72 hours.

\section{Inclusion Criteria}

- All the term neonate of birth asphyxia who $\geq 37$ weeks of gestation.

\section{Exclusion Criteria}

- Preterm neonates

- Jitteriness in neonates

- Tetanic spasms in neonates

- Neonatal seizure other than birth asphyxia.

- Newborn with congenital anomalies

Sample size: The sample size was determined using the following formula

$\mathrm{N}=4 \mathrm{pq} / \mathrm{L} 2$

$N=4 \times 27 \times 73 /(5) 2=315$

$N=$ required sample size

$P=$ Estimated prevalence of birth asphyxia $27 \%$

(Prevalence in Indian Year 2017) [42]

$Q=100-p$

$L=$ Margin error at 5\% (Standard value of 0.05)

Methodology: A pre-structured proforma is used to record the information from the individual. After getting the consent from the parent's clinical data collected and inter in the proforma which includes age, sex, religion presenting complaints, type and duration of seizure, demographic details and examination, a maternal history risk factor for perinatal asphyxia age, weight, maternal education, preeclampsia, eclampsia, diabetes in mother, maternal infection, Multiple gestations, finding on admission are noted according to study proforma. Magnesium levels were sent for all the patients along with other electrolytes. All information is recorded in a pre-designed proforma.

Data Collection Procedure: Detailed antenatal history, i.e. maternal age, past medical history, parity, gestational age, history of illness during pregnancy, any medication is taken during pregnancy; antenatal history viz. evidence of fetal distress, Apgar score, type of delivery, medication given to mother during delivery was recorded on working proforma. 
Baseline characteristics of enrolled neonates like sex, gestational age, weight, head circumference, and length were recorded on working proforma at admission. Clinical details of each seizure episode reported by the mother and subsequently observed by the resident doctors on duty were recorded i.e. age at onset of seizures, duration of seizure, number, and type of seizure. Venous blood was collected as soon as possible and $\mathrm{Mg}++$ levels were done in all babies before instituting any specific treatment.

\section{Investigations}

01. Serum electrolytes were done on an emergency basis, $\mathrm{S}$. Mg was done.

In selected cases

01. CSF Analysis: If septicemia or meningitis was suspected. LP was done and CSF was analyzed for color, turbidity, protein, sugar, total and differential cell count, and culture. Neonatal meningitis was diagnosed if the CSF culture showed the growth of organisms.

02. Chest X-ray was done to rule out meconium aspiration syndrome and respiratory distress syndrome.

03. USG/ CT scan /MRI brain examination was done in all babies with neonatal seizures to rule out $\mathrm{ICH}$, hydrocephalus, congenital anomalies of the brain, and infarction.

04. EEG done whenever indicated to find out etiology.

Laboratory Evaluation: After history taking and clinical examination, blood samples are collected from the patient for serum magnesium.

Statistical analysis: Collected data will be tabulated graphically displayed. Percentage, arithmetic mean and standard deviation to be calculated and data statistically analyzed using SPSS version 21 (statistical package for social sciences). Interferential analysis for quantitative variables to be done using an independent ' $T$ ' test whereas analysis for qualitative data is done using the chi-square test. Statistical significance is set at ' $p$ ' $<0.05$. Data will be analyzed using standard methods. Consent will be taken from the attendants before enrolling the baby in the study.

\section{Results}

\section{Table-1: Age-wise} hypomagnesemia.

\begin{tabular}{|l|l|l|}
\hline \multicolumn{1}{|c|}{ Age (days) } & \multicolumn{1}{|c|}{ N } & \multicolumn{1}{|c|}{ Percent } \\
\hline 1 day & 4 & 50.0 \\
\hline 2 days & 0 & 0 \\
\hline 3 days & 4 & 50.0 \\
\hline Total & 8 & 100.0 \\
\hline
\end{tabular}

In the present study, hypomagnesemia was present in 4 patients out of 8 pts $(50 \%)$ on day and day 3 . There were no subjects who had hypomagnesemia on day 2.

Table-2: Association of hypomagnesemia with age.

\begin{tabular}{|l|l|l|l|l|}
\hline \multicolumn{2}{|c|}{} & \multicolumn{2}{|c|}{ Mg level } & \multirow{2}{*}{ Total } \\
\cline { 3 - 4 } \multicolumn{2}{|c|}{} & Hypomagnesemia & Normal & \\
\hline \multirow{4}{*}{ Age (days) } & \multirow{2}{*}{ day } & 4 & 67 & 71 \\
& & $50.0 \%$ & $21.8 \%$ & $22.5 \%$ \\
\cline { 3 - 5 } & 2 days & 0 & 169 & 169 \\
& & $0 \%$ & $55.0 \%$ & $53.7 \%$ \\
\cline { 3 - 5 } & \multirow{2}{*}{ days } & 4 & 71 & 75 \\
\hline & $50.0 \%$ & $23.1 \%$ & $23.8 \%$ \\
\hline Total & 8 & 307 & 315 \\
& $100.0 \%$ & $100.0 \%$ & $100.0 \%$ \\
\hline
\end{tabular}

$\div 2$ Applied $\div 2$ test for significance. Value $=9.515 ; \mathrm{p}-$ value $=0.009$; consider very significant. On day one 4 out of 71 patients had hypomagnesemia. On day 2 no patient had hypomagnesemia, while on day three 4 patients had hypomagnesemia out of 75 . A significant difference was found in hypomagnesemia on day 1 and day 2 as well as day 2 and day 3 .

Table-3: Prevalence of hypomagnesemia on basis of severity of birth asphyxia.

\begin{tabular}{|l|l|l|}
\hline \multicolumn{1}{|c|}{ HIE Grade } & N & \multicolumn{1}{|c|}{ Percent } \\
\hline I & 0 & 0.0 \\
\hline II & 4 & 50.0 \\
\hline III & 4 & 50.0 \\
\hline Total & 8 & 100.0 \\
\hline
\end{tabular}

Table-4: Association of hypomagnesemia and severity of birth asphyxia.

\begin{tabular}{|l|l|l|l|l|}
\hline \multicolumn{2}{|c|}{} & \multicolumn{2}{|c|}{ Mg level } & \multirow{2}{*}{ Total } \\
\cline { 3 - 4 } \multicolumn{2}{c|}{} & Hypomagnesemia & Normal & \\
\hline \multirow{2}{*}{ HIE Gd } & I & 0 & 76 & 76 \\
& & $0 \%$ & $24.8 \%$ & $24.1 \%$ \\
\cline { 2 - 4 } & \multirow{2}{*}{ II } & 4 & 200 & 204 \\
& & $50.0 \%$ & $65.1 \%$ & $64.8 \%$ \\
\cline { 2 - 4 } & III & 4 & 31 & 35 \\
& & $50.0 \%$ & $10.1 \%$ & $11.1 \%$ \\
\hline Total & 8 & 307 & 315 \\
& & $100.0 \%$ & $100.0 \%$ & $100.0 \%$ \\
\hline
\end{tabular}

Hypomagnesemia was present in $4(50 \%)$ patients of both HIE grade II and III out of 8 patients and no 
Hypomagnesemia was present in HIE grade I.

In HIE grade II 4 patient had hypomagnesemia out of $204(64.8 \%)$ patient and no hypomagnesemia was found in the patient of HIE grade I while 4 patient had hypomagnesemia of HIE grade III out of $35(11.1 \%)$ patient A significant difference was found in hypomagnesemia of HIE grade I and II and HIE grade I and III.

Table-5: Association of hypomagnesemia and birth asphyxia.

\begin{tabular}{|l|l|l|}
\hline \multicolumn{1}{|c|}{ Mg level } & \multicolumn{1}{c|}{ N } & \multicolumn{1}{c|}{ Percent } \\
\hline Hypomagnesemia & 8 & 2.5 \\
\hline Normal & 307 & 97.5 \\
\hline Total & 315 & 100.0 \\
\hline
\end{tabular}

In the present study $8(2.5 \%)$ patients had hypomagnesemia out of 315 .

Table-6: Association of Serum sodium level and $S$. magnesium level.

\begin{tabular}{|c|c|c|c|c|}
\hline & & \multicolumn{2}{|c|}{ Mg level } & \multirow[t]{2}{*}{ Total } \\
\hline & & Hypomagnesemia & Normal & \\
\hline \multirow[t]{6}{*}{ Na level } & Hyponatremia & 0 & 20 & 20 \\
\hline & & $0 \%$ & $6.5 \%$ & $6.3 \%$ \\
\hline & Normal & 8 & 283 & 291 \\
\hline & & $100.0 \%$ & $92.2 \%$ & $92.4 \%$ \\
\hline & Hypernatremia & 0 & 4 & 4 \\
\hline & & $0 \%$ & $1.3 \%$ & $1.3 \%$ \\
\hline \multirow{2}{*}{\multicolumn{2}{|c|}{ Total }} & 8 & 307 & 315 \\
\hline & & $100.0 \%$ & $100.0 \%$ & $100.0 \%$ \\
\hline
\end{tabular}

Applied $\div 2$ test for significance. $\div 2$ value $=0.677 ; p$ value $=0.713$; consider not significant.

None of the patients had hyponatremia and hypomagnesemia

None of the patients had hypernatremia and hypomagnesemia

All patients having hypomagnesemia had normal sodium level, there was no significant association between sodium and magnesium level.

Table-7: Association of hypomagnesemia and antenatal high-risk factor in mother

\begin{tabular}{|l|l|l|l|l|}
\hline \multicolumn{2}{|c|}{} & \multicolumn{2}{|c|}{ Mg level } & \multirow{2}{*}{ Total } \\
\cline { 2 - 4 } \multicolumn{2}{|c|}{} & Hypomagnesemia & Normal & \\
\hline H/o risk in mother & Yes & 0 & 4 & 4 \\
& & $0 \%$ & $1.3 \%$ & $1.3 \%$ \\
\cline { 2 - 5 } & No & 8 & 303 & 311 \\
& & $100.0 \%$ & $98.7 \%$ & $98.7 \%$ \\
\hline Total & 8 & 307 & 315 \\
& $100.0 \%$ & $100.0 \%$ & $100.0 \%$ \\
\hline
\end{tabular}

Applied Fisher exact test for significance. pvalue $=1.000$; consider not significant.

No patient had an antenatal high-risk factor in mother who had hypomagnesemia; there was no significant association between high-risk factors and hypomagnesemia.

Table-8: Association of meningitis and hypomagnesemia.

\begin{tabular}{|l|l|l|l|l|}
\hline \multicolumn{2}{|c|}{} & \multirow{2}{*}{ Mg level } & \multicolumn{2}{|c|}{ Total } \\
\cline { 3 - 5 } \multicolumn{2}{|c|}{} & & Hypomagnesemia & Normal \\
\hline \multirow{3}{*}{ Meningitis } & Yes & 0 & 20 & 20 \\
& & $0 \%$ & $6.5 \%$ & $6.3 \%$ \\
\cline { 2 - 5 } & No & 8 & 287 & 295 \\
& & $100.0 \%$ & $93.5 \%$ & $93.7 \%$ \\
\hline Total & 8 & 307 & 315 \\
& $100.0 \%$ & $100.0 \%$ & $100.0 \%$ \\
\hline
\end{tabular}

Applied $\div 2$ test for significance. $\div 2$ value $=0.557 ; p$ value $=0.456$; consider not significant.

In the present study, none of the patients had meningitis and hypomagnesemia; there was no significant association between meningitis and serum magnesium level.

Table-9: Association of Serum magnesium level and outcome.

\begin{tabular}{|l|l|l|l|l|}
\hline \multicolumn{2}{|c|}{} & \multicolumn{2}{|c|}{ Mg level } & \multirow{2}{*}{ Total } \\
\cline { 3 - 4 } \multicolumn{2}{|c|}{} & Hypomagnesemia & Normal & \\
\hline \multirow{4}{*}{ Outcome } & Expired & 0 & 32 & 32 \\
& & $0 \%$ & $10.4 \%$ & $10.2 \%$ \\
\cline { 3 - 5 } & Discharge & 8 & 275 & 283 \\
& & $100.0 \%$ & $89.6 \%$ & $89.8 \%$ \\
\hline Total & 8 & 307 & 315 \\
& $100.0 \%$ & $100.0 \%$ & $100.0 \%$ \\
\hline
\end{tabular}

Applied $\div 2$ test for significance. $\div 2$ value $=0.928 ; p$ value $=0.335$; consider not significant. In the present study, no patient had hypomagnesemia who got expired, there was no significant association between serum magnesium level and outcome of the patient.

\section{Discussion}

In the present study, 315 neonates with birth asphyxia were studied in 1 year. Both intramurally and extramurally delivered babies were included in this study. Hypomagnesemia was a significant cause of neonatal seizures. Most of the neonates with hypomagnesemia had associated hypocalcemia. It's necessary to estimate level supplementation has been suggested to have a neuroprotective function in developing the brain [16]. 
There was a gradual rise in Mg levels with postnatal age, in both preterm infants with birth weights appropriate for gestational age and infants who were small for gestation age. Decreased $\mathrm{Mg}$ levels were observed in infants who were small gestational age and in infants born of toxemic mothers [17].

Higher average serum magnesium levels and decreased risk for long term abnormal motor examination ( $p=0.037$ ). A lower risk for epilepsy in the group with higher magnesium levels did not reach statistical significance $(p=0.06)$. This study demonstrates a correlation between higher neonatal magnesium levels and decreased risk for long term abnormal motor exam. Larger studies are needed to evaluate the hypothesis that of magnesium in addition to calcium in all neonates with seizures [18].

Magnesium sulfate administered antenatally has been found to reduce rates of cerebral palsy and given to the before preterm birth. [19].

Also delayed initiation of breastfeeding including decrease infant suckling behavior in the baby of an eclamptic mother [20]. Several animal model studies suggest that magnesium could play neuroprotective roles in the developing vertebrate CNS [21].

There are several neonatal complications (bradycardia, hypotonia, birth asphyxia, intubation in the delivery room, neonatal intensive care requirement) on increasing doses of magnesium sulfate in eclamptic mother are significantly related to increasing serum magnesium levels.

Overall, the low-dose magnesium sulfate regimen was safe in the management of eclamptic mothers, without toxicity to their neonates [22].

Gathwala et al randomly assigned forty terms, appropriate for gestational age babies with severe birth asphyxia (1 $\mathrm{min}$ Apgar score $<3$ and $5 \mathrm{~min}$ Apgar score $<6$ ), to either the study group or the control group. They found that $\mathrm{Mg}$ levels at birth in the babies with birth asphyxia were not different from those reported in normal neonates.

Injection MgS04, administered in a dose of 250 $\mathrm{mg} / \mathrm{kg}$ and $125 \mathrm{mg} / \mathrm{kg}$ as an intravenous infusion was safe, and the $\mathrm{Mg}$ levels obtained were in the range considered to be neuroprotective Similarly, Plasma Mg levels in babies with hypoxic-ischaemic encephalopathy are similar to those in normal neonates [23].
Bhat et al in their longitudinal randomized, placebocontrolled trial tested whether postnatal magnesium sulfate treatment could improve neurologic outcomes at discharge among term neonates with severe perinatal asphyxia.

The study subjects were 40 terms (> 37 weeks) neonates. Their findings demonstrate that postnatal treatment with magnesium sulfate improves neurologic outcomes at discharge for term neonates with HIE [24].

However, Galvin et al in his study suggested that magnesium treatment after perinatal HIE damage in the rat is not markedly neuroprotective for striatal medium spiny neurons [25].

A previous study in their prospective study of 60 term neonates with HIP suggested that serum total magnesium does not predict outcome in neonatal hypoxic-ischemic encephalopathy [26].

Elizabeth et al, from the cohort of 500 babies, measured total magnesium levels, and found significantly lower levels among LBW, lowest in preterm followed by term-LBW, compared to term controls [27]. Parathyroid hormone PTH is synthesized by the chief cells and stored in secretory granules. Serum PTH concentrations increase postnatally coincidentally with the fall in serum $\mathrm{Ca}$ in both term and preterm infants [28-30].

It has a significant circadian periodicity, spontaneous episodic pulsatility, with distinct peak property and a significant temporal coupling with serum iCa and $\mathrm{P}$ concentrations and prolactin secretion. In physiologic terms, PTH acts synergistically with $1,25(\mathrm{OH}) 2 \mathrm{D}$ and is the most important regulation of extracellular $\mathrm{Ca}$ concentration.

PTH acts directly on bone and kidney and indirectly with the fall in serum $\mathrm{Ca}$ in both term and preterm infants [31-34]. It has a significant circadian periodicity, spontaneous episodic pulsatility, with distinct peak property and a significant temporal coupling with serum $\mathrm{iCa}$ and $\mathrm{P}$ concentrations and prolactin secretion.

In physiologic terms, PTH acts synergistically with $1,25(\mathrm{OH}) 2 \mathrm{D}$ and is the most important regulation of extracellular Ca concentration. PTH acts directly on bone and kidney and indirectly on intestine that is PTH-induced mobilization of $\mathrm{Ca}$ from bone and increased renal distal tubular reabsorption of $\mathrm{Ca}$ and increased intestinal $\mathrm{Ca}$ absorption secondary to increased 1,25 $(\mathrm{OH}) 2 \mathrm{D}$ production. 
A decrease in serum magnesium stimulates PTH secretion, although chronic hypomagnesemia inhibits secretions of PTH. Hypomagnesemia is also associated with an increased target tissue resistance to PTH probably from inactivity of adenylate cyclase, an $\mathrm{Mg}$ requiring enzyme.

Vitamin $D$ and its metabolites, 25-hydroxy vitamin $\mathrm{D}(25-\mathrm{OHD})$ and $1,25(\mathrm{OH}) 2 \mathrm{D}$, acting through Vit D receptors, decrease the level of PTH mRNA [35-36]. Additional systemic factors (growth hormone, insulin-like growth factor 1 , estrogen, progesterone, calcitonin, cortisol, catecholamines, prostaglandins, and somatostatin) and local factors (IL-1) modulate PTH secretion and function.

\section{Hypomagnesemia}

Hypomagnesemia is present when serum total magnesium is less than $0.6 \mathrm{mmol} / \mathrm{L}(1.5 \mathrm{mg} / \mathrm{dL})$.

\section{Causes of neonatal hypomagnesemia}

01. Decreased tissue accretion

- Infants of mothers with insulindependent diabetes or hyperparathyroidism

- Small for gestational age infants

- Chronic maternal magnesium deficiency

02. Decreased absorption

- Extensive small intestine resection

- Specific intestinal magnesium malabsorption

03. Increased loss

- Intestinal fistula or diarrhea

- Hepatobiliary disorders

- Decreased renal tubular reabsorption

Primary- transient receptor potential channel protein mutation, renal tubulopathies with hypo or hypercalciuria

Secondary - extracellular fluid compartment expansion, osmotic

Diuresis, drugs (e.g.: loop diuretic, aminoglycoside, ibuprofen overdose).

In the present study prevalence of hypomagnesemia was $2.5 \%$ in birth asphyxia, a study done by Suganthi $V$ et al found the prevalence of hypomagnesemia was $5.3 \%$ [37] and a study done by Saha $D$ et al concluded prevalence of
Hypomagnesemia in birth asphyxia was $10 \%$ which was higher than the present study [38].

In the present study, 4 patient had hypomagnesemia out of $71(22.5 \%)$ patient on the day of life 1 and no patient had hypomagnesemia out of $169(53.7 \%)$ patient on day 2 while 4 patient had hypomagnesemia out of $75(23.8 \%)$ on day of 3.

In the present study, 4 patients had hypomagnesemia out of $71(22.5 \%)$ patient on the day of life 1 and no patient had hypomagnesemia out of $169(53.7 \%)$ patient on day 2 while 4 patient had hypomagnesemia out of $75(23.8 \%)$ on day 3 .

In the present study, severe birth asphyxia had more hypomagnesemia as in other studies done by Nasreen Khalesi et al which suggested birth asphyxia had more hypomagnesemia [39]. The result of the study was similar to the present study.

\section{Conclusion}

From the results obtained in the current study, it can be concluded that hypomagnesemia was more on day 1 and day 3 . Severe birth asphyxia had more prevalence of Hypomagnesaemia.

\section{What does the study add to the existing knowledge}

There have not been a lot of studies regarding the prevalence of hypomagnesemia and the association of hypomagnesemia with age gender, complications risk factor, and other electrolytes.

In previous studies, the role of therapeutic magnesium supplementation has been seen but not recommended so it is recommended that there should be more studies regarding hypomagnesemia in birth asphyxia and the association of hypomagnesemia with other parameters.

\section{Author's contribution}

Dr. Karm chand Gandhi: Concept, study design

Dr. Abhishek Kumar Singh: Manuscript preparation

Dr. Anita Mehta: Data analysis

Dr. Bhoopendra Sharma: Manuscript preparation

Dr. Harish Chandra Tiwari: Manuscript review. 


\section{Reference}

01. Kumar A, Gupta A. Clinico-etiological and EEG profile of neonatal seizures. Indian J Pediatr. 2007;74(1)33-37.

doi: $\quad 10.1007 / \mathrm{s} 12098-007-0023-0 \quad$ [Crossref]

02. Kumar A, Gupta V, Kacchawaha JS, Singla PN. Biochemical abnormalities in neonatal seizures. Indian Pediatr. 1995;32;424-428.

[Crossref]

03. Antonucci R, Prcella A, and Pilloni MD. Perinatal asphyxia in term newborn. J Pediatr Neonat Individual Med. 2014;3(2)e030269.

doi: $10.7363 / 030269$ [Crossref]

04. Aslam HM, Saleem S, Afzal R, Iqbal U, Saleem SM, Shaikh MW, et al. Risk factors of birth asphyxia. Ital J Pediatr. 2014;40(1)94.

doi: $\quad 10.1186 / \mathrm{s} 13052-014-0094-2 \quad$ [Crossref]

05. Manual of neonatal care. Cloherty 7th edition, Incidence rate of neonatal seizure. Lippincott Williams \& Wilkins, a Wolters Kluwer. 2012. [Crossref]

06. Jajoo D, Kumar A, Shankar R, Bhargana. Effect of birth asphyxia in serum Magnesium levels in neonate. Indian J Pediatr. 1995;62(4)455-459.

doi: $10.1007 /$ BF02755067 [Crossref]

07. Tekgul H, Gauvreau K, Soul J, Murphy L, Robertson R, Stewart J, et al. The current etiologic profile and neurodevelopmental outcome of seizures in term newborn infants. Pediatr. 2006;117(4)1270-1280.

doi: 10.1542/peds.2005-1178 [Crossref]

08. Choi DW, Rothman SM. The role of glutamate neurotoxicity in hypoxic-ischemic neuronal death. Ann Rev Neurosci. 1990;13(1)171-182.

doi: $\quad 10.1146 /$ annurev.ne.13.030190.001131

[Crossref]

09. Ichiba H, Yokoi T, Tamai H, Ueda T, Kim TJ, Yamano T. Neurodevelopment outcome of infants with birth asphyxia treated with magnesium sulfate. Pediatr. 2006;48(1)70-75. doi: $\quad 10.1111 / j .1442 .2006 .02167 . x \quad$ [Crossref]
10. Gulogfnard JP, Sulyok E. Renal Morphogenesis and development of renal function, In- gleason CA, Devaskar SU, eds, Avery's Disease of the Newborn. 9th ed, Philadelphia, PA; Elsevier Saunders. 2012;1165-1175.

[Crossref]

11. Douglas-Escobar MN, Weiss MD. Hypoxicischemic encephalopathy- A review for the clinician. JAMA Pediatr. 2015;169(4)397-403. doi: 10.1001/ jamapediatrics.2014.32659 [Crossref]

12. Reinhart RA. Magnesium metabolism- A review with special reference to the relationship between intracellular content and serum levels. Arch Int Med. 1988;148(11)2415-2420.

doi: $\quad 10.1001 /$ archinte.148.11.2415 [Crossref]

13. Musso CG. Magnesium metabolism in health and disease. Int Urol Nephrol. 2009;41(2)357-362.

doi: $\quad 10.1007 / \mathrm{s} 11255-009-9548-7 \quad$ [Crossref]

14. Kaze FF, Stoermann CC. Magnesium metabolism disturbances. Rev Med Suisse. 2007;3(101)6056, 608, 610-1.

[Crossref]

15. Moe SM. Disorders involving calcium, phosphorus and magnesium. Prim Car. 2008;35(2)215-237.

doi: 10.1016/j.pop.2008.01.007 [Crossref]

16. Rouse DJ, Hirtz DG, Thom E, Varner MW, Spong $\mathrm{CY}$, Mercer BM, et al. A randomized, controlled trial of magnesium sulfate for the prevention of cerebral palsy. N Engl J Med. 2008;359(9)895905.

doi: 10.1056/NEJMoao8201187 [Crossref]

17. Doyle LW, Crowther CA, Middleton P, Marret S, Rouse D. Magnesium sulphate for woman at risk of preterm birth for neuroprotection of the fetus. Cochrane Database Syst rev. 2009;21(1)CD004661. doi:10.1002/14651858.CD004661_[Crossref]

18. Tsang RC, Oh W. Serum magnesium levels in low birth weight infants. Am J Dis Child. 1970;120(1)44-48.

doi:10.1001/archpedi. 1970.02100060078010

[Crossref] 
19. Maged $M$, Costantine MD. Effects of antenatal exposure to magnesium sulphate on neuroprotection and mortality in preterm infants- Meta-analysis. Obstet Gynecol. 2009;114(2)354-364.

doi: 10.1097/AOG.obo13e3181ae98c2 [Crossref]

20. Demirci J, Schmella M, Glasser M, Bodnar L, Himes KP. Delayed Lactogenesis II and potential utility of antenatal milk expression in women de veloping late-onset preeclampsia- a case series. BMC Pregnancy Childbirth. 2018;18(1)68.

doi: 10.1186/s12884-018-1693-5 [Crossref]

21. Stevenson TJ, Trinh T, Kogelschatz C, Fujimoto E, Lush ME, Piotrowski $T$, et al. Hypoxia disruption of vertebrate CNS pathfinding through ephrinB2 Is rescued by magnesium. PLoS Genet. 2012;8(4)e1002638.

doi: 10.1371/journal.pgen.1002638 [Crossref]

22. Abbassi-Ghanavati M, Alexander JM, McIntire DD, Savani RC, Leveno KJ. Neonatal effects of magnesium sulfate given to the mother. Am J Perinatol. 2012;29(10)795-800.

doi: $10.1055 / \mathrm{s}-0032-1316440$ [Crossref]

23. Gathwala G, Khera A, Singh I. Magnesium therapy in birth asphyxia. Indian J Pediatr. $2006 ; 73(3) 209-212$.

doi: $10.1007 /$ BF02825482 [Crossref]

24. Bhat MA, Charoo BA, Bhat JI, Ahmad SM, Ali SW. Magnesium sulfate in severe perinatal asphyxia- a randomized, placebo-controlled trial. Pediatr. 2009;123(5)e764-e769.

[Crossref]

25. Galvin KA, Oorschot DE. Continuous low-dose treatment with brain-derived neurotrophic factor or neurotrophin-3 protects striatal medium spiny neurons from mild neonatal hypoxia/ischemia- a stereological study. Neurosci. 2003;118(4)1023-1032.

doi: $10.1016 / s 0306-4522(03) 00066-6 \quad$ [Crossref]

26. Kumr D, Yelamali B, Pol Y. Serum calcium and magnesium levels in predicting short term outcome of term neonates with hypoxic ischemic encephalopathy. Med Innovatica. 2018;7(1)44-47.

[Crossref]
27. Elizabeth KE, Krishnan V, Zachariah $P$. Auxologic, Biochemical and Clinical (ABC) Profile of Low Birth Weight Babies-A 2-year Prospective Study. J Trop Pediatr. 2007;53(6)374-382.

[Crossref]

28. Saggesc G, Baroncelli GI, Bertelloni S, Cipolloni C. Intact parathyroid hormone levels during pregnancy, in healthy term neonates and in hypocalcemic preterm infants. Acta Paediatr Scan. $1991 ; 80(1) 36-41$. doi: 10.1111/j.1651-2227.1991.tb11726.x [Crossref]

29. Rubin LP, Posillico JT, Anast CS, Brown EM. Circulating levels of biologically active and immunoreactive intact parathyroid hormone in human newborns. Pediatr Res. 1991;29(2)201207.

doi: 10.1203/00006450-199102000-00020 [Crossref]

30. Mimouni F, Loughead JL, Tsang RC, Khoury J, et al. Postnatal surge in serum calcitonin concentrations- no contribution to neonatal hypocalcaemia in infants of diabetic mothers. Pediatr Res. 1990;28(5)493-495.

doi: 10.1203/00006450-199011000-00015 [Crossref]

31. Ilves $P$, Blennow $M$, Kütt $E$, Mägi $M L$, Kudrjavtseva G, Lagercrantz $H$, Talvik T. Concentrations of magnesium and ionized calcium in umbilical cord blood in distressed term newborn infants with hypoxic-ischemic encephalopathy. Acta Pædiatrica. 1996;85(11)1348-1350. doi: 10.1111/j.1651-2227.1996.tb13923.x [Crossref]

32. Yadav N, Damke S. Study of risk factors in children with birth asphyxia. Int J Contemp Pediatr. 2017;4(2)518-526.

doi: 10.18203/2349-3291.ijcp20170701 [Crossref]

33. Dalal CA, Bodar NL. A study on birth asphyxia at tertiary health centre. Natl J Med Res. 2013;3(4)374-376.

[Crossref]

34. Padaychee N, Ballot DE. Outcomes of neonates with perinatal asphyxia at a tertiary academic hospital in Johannesburg. South Africa. South African J Ch Health.

2013;7(3)89-94 [Crossref] 
35. Shalev H, Phillip M, Galil A, Carmi R, Landau D. Clinical presentation and outcome in primary familial hypomagnesaema. Arch Dis Child. $1998 ; 78(2) 127-130$.

doi: $10.1136 /$ adc.78.2.127 [Crossref]

36. Mathias RS, Nguajen HT, Zhang MY, Portale AA. Reduced expression of the renal calcium-sensing receptor in rats with experimental chronic renal insufficiency. J Am Soc Nephrol. 1998;9(11)2067-2074.

[Crossref]

37. Suganthi V, Vikneshwari K, Thivya G. Prevalence of hypomagnesemia in neonatal seizures in a tertiary care hospital in South India. Pediatr Rev Int J Pediatrics Res. 2017;4(01)64-68.

doi:10.17511/ijpr.2017.01.13 [Crossref]
38. Saha D, Ali MA, Haque MA, Ahmed MS, Sutradhar PK, Latif T, Sarkar D, Husain F. Association of hypoglycemia, hypocalcemia and hypomagnesemia in neonates with perinatal asphyxia. Mymensingh Med J. 2015;24(2)244250.

[Crossref]

39. Khalesi N, Namiranian P, Farahani Z. The Frequency of Early and Late Hypocalcemia Among Hospitalized Newborns in An Iranian Hospital. Shiraz E Med J. 2015;16(6).

doi: $10.17795 /$ semj28080 [Crossref] 